Preprints of the

Max Planck Institute for

Research on Collective Goods

Bonn 2006/8

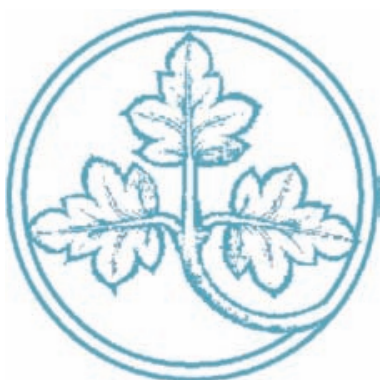

Wage Differentials,

Fairness and Social

Comparison:

An experimental study of the Co-Employment of Permanent and Temporary Agency Workers

Dorothea Alewell /

Andreas Nicklisch

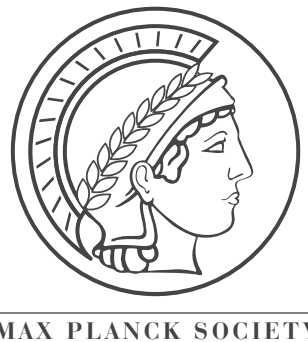




\section{Wage Differentials, Fairness and Social Comparison: An experimental study of the Co-Employment of Permanent and Temporary Agency Workers}

Dorothea Alewell / Andreas Nicklisch

March 2006 


\title{
Wage Differentials, Fairness, and Social Comparison: An experimental study of the Co-Employment of Permanent and Temporary Agency Workers ${ }^{\dagger *}$
}

Dorothea Alewell, Friedrich Schiller University Jena, Chair for Business Administration, Human Resource Management and Organization; Carl-Zeiss-Strasse 3, D-07737 Jena, Germany; email d.alewell@wiwi.uni-jena.de

Andreas Nicklisch, Max Planck Institute for Research on Collective Goods; KurtSchumacher-Strasse 10, D-53315 Bonn, Germany; email nicklisch@coll.mpg.de

\begin{abstract}
Recent experimental literature in labor economics shows that fairness concerns make a substantial difference for working decisions. Our study systematically explores how the existence of multiple fairness foci influences wage setting and acceptance thresholds. Particularly, we focus on the effect of horizontal fairness concerns, i.e., the wage comparison among employees. For our experiment, we use an institutional design of wage negotiations among employers, employees and temporary agency workers. Working agencies hire these workers and rent them out to firms. Thereby, we create a heterogeneous background of the labour force. Although temporary agency workers do the same work, typically, they receive lower wages due to the intermediate agency. The results of our laboratory experiments indicate that the availability of information concerning co-employee's wage offers strongly influences the wage set and participants' acceptance of contracts. Whereas the relation of average wages is not influenced by the order of the decisions, the absolute level of wages is dependent on the decisions. We find that temporary agency workers who decide on a wage offer after permanent employees receive a premium in addition to their wages, while permanent employees take a cut in wages if they get their wage offer after temporary workers have decided on their offers. These results are more influenced by self-regarding social comparison preferences than by other-regarding horizontal fairness concerns.
\end{abstract}

\section{Keywords}

Experimental economics, horizontal fairness norms, labour economics, social preferences, vertical fairness norms

JEL

C92, J33, M12, M52

\footnotetext{
${ }^{\dagger}$ We dedicate this article to our colleague, Wiebke Kuklys, who died while we were planning this study.

* We are very grateful for comments and suggestions of Christoph Engel, Martin Hellwig and Stefan Magen.
} 


\section{Introduction}

Fairness norms are highly relevant for work-related decisions in organizations and on the labour market. Although there has been much in-depth research on fairness issues, ${ }^{1}$ many aspects of fairness behaviour are still not very well understood. ${ }^{2}$ This is especially true for the relevance of fairness judgements in complex, rich settings where multiple reference points could guide behaviour. In the following, as one example of the wider class of situations with multiple fairness foci, we experimentally analyse the relation between two reference points for social preferences, vertical fairness considerations and horizontal fairness considerations in a complex ultimatum game setting with three interrelated ultimatum games. Hereby, we use the term "vertical fairness considerations" for the relation between the outcome distributions among proposers and responders in ultimatum games and responders' acceptance thresholds. By contrast, we use the term "horizontal fairness concerns" to characterize the relation between the outcome distributions among several responders and their acceptance thresholds. As one example, we consider the co-employment of regular employees and temporary agency workers. This situation is especially interesting since there are vertical foci, e.g., the payoffs of the respective contract partners (employee and employer, temporary work agency and temporary worker) and horizontal foci for fairness judgements, e.g., the absolute or relative wage of the other worker, with or without reference to other differences between the two types of workers. Moreover, this environment allows for different interpretations of fairness considerations. We model a situation where employees have to do the same work. Therefore, one may argue that only equal wages would treat temporary and regular employees fairly. On the other hand, in this institutional setting, there are obvious reasons that the wages of temporary and regular employees differ, since there is an intermediating agency between employers and temporary employees. Employers have to pay the agency as well, so that one can argue that wages for temps have to deviate from wages of regular employees. Our treatments systematically vary the sequential order of decisions, and, thereby, the available information about some of these possible fairness foci. We can, thus, derive information about the relevance of these elements in the formation of fairness judgements.

\footnotetext{
${ }^{1}$ To name only a few more recent papers, for example, Bolten \& Ockenfels, 2000, Dickinson \& Tiefenthaler, 2002, Fehr \& Schmidt, 1999, Gächter \& Fehr, 2002, Kahnemann et al., 1986, Konow, 1996, 2000, 2001, 2003, Rabin 1993, and Scott, 2003.

2 For an early paper from the perspective of psychology, see Leventhal (1980); he identifies the multidimensionality of fairness concepts as one of the three major problems with equity theory.
} 
The co-employment of hired and rented hands is only one example from a wider class of situations with multiple fairness foci. Particularly, we choose it as our example since it is currently of considerable political relevance in the European Union. Several institutional changes have been recently introduced that aim at decreasing unemployment by furthering temporary agency work. As an example, in order to increase the acceptance of temporary employment, Germany introduced the compulsory equal treatment of permanent and temporary employees if no collective agreement applies (Alewell et al., 2004).

The fairness and justice literature identifies different fairness norms, reference points or justice principles that can potentially guide the judgement on whether allocations are fair; for example, equality and needs, equity and desert, efficiency or accountability (Konow, 2003), absolute differences in pay-off versus relative pay-off (Bolten \& Ockenfels, 2000, Fehr \& Schmidt, 1999), changes in one's own pay-off versus pay-off relative to others (Scott, 2003), effects of entitlements (Kahnemann et al., 1986), total surplus or net surplus over reservation utility, horizontal fairness between different workers or vertical fairness between the employer and worker (Knez \& Camerer, 1995). Despite the multiple insights on the effect of the context on fairness evaluations (for an in-depth overview, see Konow, 2003), specific hypotheses about the relevance of differing fairness norms are still to some extent speculative, since there are many situational factors that influence fairness evaluations - for example, the scope of the comparisons, the weighting of justice principles, competing forces such as fairness and self-interest and the relative importance of procedural and distributive justice (Konow, 2003). ${ }^{3}$ Therefore, at this point in the research, much can still be learnt from experimental studies with multiple fairness foci that systematically vary aspects of the situation.

Apparently, within organizations and on labour markets, multiple foci of fairness are relevant in many contexts, e.g., regarding wage decisions concerning employees with differing sets of human capital investment and heterogeneous needs doing the same work, layoff decisions concerning workers with differing seniority, family responsibilities, outside options and performance, training investment decisions for employees with differing performance, outside options and future employment perspectives. For our analysis, we chose the issue of the co-employment of regular employees and temporary agency workers under 
heterogeneous contracts, since this allows us to investigate not only two employees, but also two employers with differing characteristics. Thus, horizontal as well as vertical social comparisons or foci for fairness judgements are available. The game theoretic solution does not hold for the standard results of standard ultimatum games with two players and outside options of zero. Rather some kind of fairness consideration will be relevant (see, for example Güth et al., 1982, Güth \& Tietz, 1990, Güth et al., 1998, Camerer, 2003). Generally, in simple two-player ultimatum games with outside options of zero, responders accept splits of between twenty and fifty percent, while lower offers are frequently rejected (Camerer, 2003).

In ultimatum games with more than two persons, multiple foci for fairness judgements may result, as horizontal or vertical comparisons could be relevant. Positive, but different, outside options of responders further add possible foci. Knez and Camerer (1995) conduct a three-player ultimatum game with one proposer offering to two responders. These have positive, but differing, outside options. Observations are based on the strategy method. Both ultimatum games are independent from each other because neither responder's decision has any direct impact on the other ultimatum game. However, the design offers opportunities for social comparison not only vertically, between proposer and responder as in standard ultimatum games, but also horizontally, between the two responders, as well. The experimental data indicate that approximately half the responders obviously conducted a social comparison between responders, while the other half of the responders, as well as proposers, did not. Consequently, this setting led to rejection rates of approximately fifty percent of all the offers, much higher rates than in other studies. The authors argue that the introduction of multiple possible foci for fairness judgements resulted in a self-serving bias (Babcock et al., 1996) or egocentric selections between these different foci of fairness judgements for each player: ${ }^{4}$ While proposers select a fairness standard which leads to relatively low offers, responders focus on reference points which lead to high offers, and therefore reject the lower offers more frequently than in the simple ultimatum game. Moreover, even for those individuals who apply social comparisons between responders, the strength of this motive seems to hinge, in a critical and complex way, on the size of the payoffs received by the proposer and the other responder. Thus, the relevance of horizontal fairness judgements - as opposed to vertical fairness standards, which are very well

\footnotetext{
${ }^{3}$ Besides situational factors, different cultural reference points for fairness (for an overview, see Camerer, 2003, chapter 2) and gender differences in fairness behavior (e.g. Dickinson \& Tiefenthaler, 2002) are found in experiments.

${ }^{4}$ Konow (2000) elaborates on these issues with respect to the 'accountability' principle of fairness.
} 
documented in the experimental literature - is quite ambiguous even for simple situations where the single ultimatum games are not directly interrelated. ${ }^{5}$ Extending this insight, we concentrate on the analysis of multiple foci for fairness judgements and construct three interrelated ultimatum games with four players, where the result of the first ultimatum game influences the third game.

Yet many different contextual elements might be relevant for the selection of fairness foci. The available information will influence the fairness judgement, as non-available information might be neglected in the decision or be substituted by ceteris paribus assumptions (see Konow, 2003). Of course, the importance of the sequential order of decisions and the availability of precise information for decisions has been analysed extensively. The theoretical analysis (e.g., Bagwell, 1995, Huck \& Müller, 2000, Schelling, 1960) predicts a strategic advantage for those parties who first decide about their share of a common pie, such that the first movers receive the entire surplus from the bargaining. However, since the work of Güth et al. (1982), it has been obvious in the experimental literature about ultimatum bargaining that there is no clear-cut first mover advantage because of the effect of vertical fairness concerns. Studies dealing with horizontal concerns attempt to differentiate among second movers, i.e., responders in sequential but independent ultimatum games. Again, theory predicts that there is neither a first responder advantage nor a second responder advantage. Yet, as shown by Charness \& Kuhn (2004), the observation of coworkers wages is quite important for workers' effort decisions. The main result is that firms react to the fact that wages become public by suppressing wage dispersion, obviously anticipating negative reactions by workers to large wage differences. Thus, wage secrecy and wage compression policies have relevant implications for firms' performance. Consequently, there is a second responder advantage; specifically, responders who observe other responders' decisions receive a premium in order to avoid negative wage discrimination, which violates their - horizontal - fairness needs.

With these results in mind - selected out of the large number of possible elements on which further research is needed - our paper focuses on the effect of the sequential order of decisions and the resulting availability of information that can be used to form reference points. We extend the setting of Charness \& Kuhn (2004) by introducing an intermediating

\footnotetext{
${ }^{5}$ Knez and Camerer (1995, p. 67, fn 2) conclude that to understand how fairness issues affect organizations, "richer games that are more like complicated organizations" would be required, with three player ultimatum
} 
agency for - temporary - employees. Thus, the fairness considerations for the relation between employer, agency and temporary employee are more complex. We avoid the salience of equivalent wage offers among employees. Rather, we will test whether there is some kind of substitution effect between horizontal and vertical fairness considerations. Particularly, we analyse the direction of horizontal fairness considerations. One may argue that players have other-regarding needs. If so, a ratio of offers substantially discriminating against any of the responders will be rejected, not only offers discriminating against themselves. On the other hand, one can think of horizontal fairness considerations as social comparison needs so that offers that would have been below the acceptance threshold when no information was available become acceptable due to a favourable horizontal comparison. Our results clearly indicate that, indeed, the public information on wages functions as a social comparison norm. Yet, there is a two-sided effect. There are both second responder advantages, as well as second responder disadvantages, due to horizontal fairness concerns. Those responders who observe decisions of other responders with higher outside options receive a premium. Apparently, proposers anticipate the horizontal fairness concerns of the observing responder and increase their offers. However, those responders who observe decisions of other responders with lower outside options receive lower wage offers, which are nevertheless acceptable due to their horizontal comparison. Thus, proposers benefit from the responders' expected needs for social comparison in this setting.

This paper is organized as follows: Section 2 introduces the model of the interdependent ultimatum game and develops the theoretical predictions. Section 3 reports the experimental design. Section 4 elaborates on hypotheses for players' behaviour and discusses counterarguments. Section 5 shows the results of the laboratory experiments, while Section 6 concludes the paper with a discussion.

\section{The model}

There are four players in our model: an employer or principal $P$, a temporary work agency $A$, an employee $a$ (hired hand) and a temporary agency worker $r$ (rented hand). For both workers, $a$ and $r$, we assume that effort and effort costs are exogenously given, and can therefore be excluded from our analysis. Wage payments are thus the only relevant decision parameters for the two employees. Both workers $i=\{r, a\}$ have positive, but differing, reservation utilities 
$U_{\mathrm{i}}$ from unemployment benefits. Employee $a$ has a larger reservation utility than temporary worker $r, U_{\mathrm{a}}>U_{\mathrm{r}}$. If employed, they both do the same work. Therefore, each worker has the same level of productivity, denoted as $\Delta$. We assume that all reservation utilities and productivity are common knowledge.

Agency $A$ can employ temporary worker $r$ and offer $r w_{\mathrm{r}}$. If $r$ accepts this offer, he is under contract with $A$ and earns $w_{\mathrm{r}}$; if not, he earns unemployment benefit $U_{\mathrm{r}}$. Employer $P$ has to decide on the wage offer $w_{\mathrm{a}}$ made to employee $a$. If $a$ accepts, employee $a$ works for $P$ and earns $w_{\mathrm{a}}$; if he does not agree, he remains unemployed and earns unemployment benefit $U_{\mathrm{a}}$. Additionally, $P$ can contract with temporary work agency $A$ to temporarily hire worker $r$. For this, he offers the agency a hiring fee $w_{\mathrm{A}}$. If $A$ accepts (conditional on $r$ 's acceptance of the contract with agency $A$ ), then worker $r$ is hired out to $P$. Otherwise, $A$ hires out $r$ for an outside option, yielding $U_{\mathrm{A}}$ for the agency. Defining

$$
\delta_{i}=\left\{\begin{array}{ccc}
1 & \text { if } & i \text { accepts } \\
0 & \text { otherwise }
\end{array}\right.
$$

for $i=\{a, r, A\}$, we can compute the profit of $P$ as

$$
\pi_{P}=\left(\delta_{A} \delta_{r}+\delta_{a}\right) \Delta-\delta_{a} w_{a}-\delta_{A} w_{A} \delta_{r} .
$$

The profit of agency $A$ is given by

$$
\pi_{A}=\delta_{r}\left(\delta_{A} w_{A}+\left(1-\delta_{a}\right) U_{A}-w_{r}\right),
$$

while rented hand $r$ earns

$$
\pi_{r}=\delta_{r} w_{r}+\left(1-\delta_{r}\right) U_{r},
$$

and hired hand $a$ receives

$$
\pi_{a}=\delta_{a} w_{a}+\left(1-\delta_{a}\right) U_{a} .
$$

Assuming $2 \Delta>U_{A}+U_{a}+2 \varepsilon$, with $\varepsilon$ denoting the smallest feasible increment, and further assuming $U_{\mathrm{A}}>U_{\mathrm{r}}+\varepsilon$, the unique subgame perfect Nash equilibrium of this game is characterized by

$$
\begin{aligned}
& w_{r}=U_{r}+\varepsilon \\
& w_{a}=U_{a}+\varepsilon \\
& w_{A}=U_{A}+\varepsilon \\
& \delta_{i}=1 \text { for } i=\{a, r, A\} .
\end{aligned}
$$

Note that the optimal wage offers are independent of the wage offers to other players, but depend solely on the reservation utilities. 
As can easily be seen by this model description, the model contains three interrelated ultimatum games. While the two ultimatum games between the two employers $P$ and $A$ and their respective employees $a$ and $r$ are independent from each other, but could be interrelated indirectly by a horizontal social comparison if participants received information about the wage offers to the other players, the result of the ultimatum game between the two employers $P$ and $A$ has a direct effect on the game between $A$ and $r$, as the renting out fee $w_{\mathrm{A}}$, if accepted, defines the size of the pie that can be divided between $A$ and $r$.

\section{Experimental designs and treatments}

The experiment was conducted at the EconLab at the University of Bonn, Germany in October, November and December 2005. ${ }^{6}$ Participants were students from Bonn University. As the experiment aims at testing for the influence of the differing fairness foci of the participants, we designed two treatments which vary the information that is available for the two employees by changing the sequential order of the decisions. In both treatments the ultimatum game between $P$ and $A$ is conducted first. Additionally, $A$ chooses the wage offer $w_{\mathrm{r}}$, and all participants are informed about offer $w_{\mathrm{A}}$ and $A$ 's decision $\delta_{\mathrm{A}}$. The order of the other two ultimatum games, however, differs in the two treatments:

i. In the treatment "staff", employer $P$ offers $w_{\mathrm{a}}$ first, and employee $a$ makes his decision $\delta_{\mathrm{a}}$. Employee $r$ is informed about $w_{\mathrm{r}}, w_{\mathrm{a}}$ and $\delta_{\mathrm{a}}$, and makes his decision.

ii. In treatment "temp", the game between agency $A$ and worker $r$ is conducted first. Employee $a$ is informed about $w_{\mathrm{a}}, w_{\mathrm{r}}$ and $\delta_{\mathrm{r}}$, and makes his decision.

The information sets can described as follows, with superscripts R and S denoting the treatments "staff" and "temp":

$$
\begin{aligned}
I_{a}^{s} & =\left\{w_{A}, \delta_{A}, w_{a}\right\} \\
I_{r}^{s} & =\left\{w_{A}, \delta_{A}, w_{a}, \delta_{a}, w_{r}\right\} \\
I_{a}^{t} & =\left\{w_{A}, \delta_{A}, w_{r}, \delta_{r}, w_{a}\right\} \\
I_{r}^{t} & =\left\{w_{A}, \delta_{A}, w_{r}\right\} .
\end{aligned}
$$

\footnotetext{
${ }^{6}$ Experiments were computerized using zTree (Fischbacher, 1999). For the recruitment of subjects, we used Orsee (Greiner, 2004).

${ }^{7}$ Participants knew about reservation utilities and productivity, which we have not explicitly mentioned here.
} 
Thus in the treatment "staff", players $r$ had information about an additional horizontal fairness focus, while in the treatment "temp", this additional information was available for players $a .^{8}$ Productivity $\Delta$ of an individual worker was set as 19 experimental currency units, while the reservation pay-offs were defined by $U_{\mathrm{a}}=3, U_{\mathrm{r}}=1$, and $U_{\mathrm{A}}=10$ experimental currency units.

Before starting the experiment, participants had sufficient time to study the instructions and ask questions privately. In the instructions we referred explicitly to wage negotiations between firms, agencies, employees and temporary employees, which made it easy for participants to understand the entire structure of the experiment. We then applied a questionnaire, which tested participants' understanding of the game and of the pay-off structure. ${ }^{9}$ Only participants with a sufficient understanding and good test results were allowed to participate in the experiment. In total, 168 subjects participated in the 14 sessions, 7 for the "staff" treatment, and 7 for the "temp" treatment. Within each session, there were 3 subjects for each role. Each participant played 15 periods of the interdependent ultimatum game. We used a stranger design and constant roles, such that participants remained in the same role throughout the entire experiment, but were anonymously grouped together anew by chance in every round. The average length of the experiment was 60 minutes. In addition to a fixed show-up fee of $€ 4$, players earned variable pay-offs according to their decisions in the game. All experimental currency units were converted at a rate of 24 units for $€ 1.00$ at the end of the experiment. Average pay-offs were $€ 7.26$ (standard deviation, hereafter abbreviated sd, 1.36) for the $P$ role, $€ 3.16$ (sd 0.75 ) for the $A$ role, $€ 5.05$ (sd 0.98) for the $a$ role, and $€ 3.08$ (sd 0.67) for the $r$ role.

\section{Hypotheses}

Starting with the results of standard ultimatum games, our first hypothesis targets vertical fairness issues between agency $A$ and temporary worker $r$, on the one hand, and between employer $P$ and employee $a$, on the other hand.

\section{$H_{1}$ (Standard vertical fairness concerns between employers and employees):}

Against the background of the cooperative Nash solution, the size of the pie that can be divided between the players of the ultimatum games has to be calculated as a surplus over the reservation pay-offs. Standard results of ultimatum games with zero reservation utilities show

\footnotetext{
${ }^{8}$ The instructions for treatment "staff" can be found in appendix A.

${ }^{9}$ See appendix B.
} 
that offers of between 20 and 50 percent of the total size of the pie are frequently made and accepted (e.g., Camerer, 2003). Combing both results, for the standard ultimatum games, i.e., between $P$ and $a$, and between $A$ and $r$, we expect proposers' offers to share the respective size of the surplus over reservation utilities approximately equally. For the upper limit, we expect 0.5 , while for the lower limit we expect 40 percent of the upper limit, i.e., 0.2 of the surplus, or

$$
\left\{\begin{array}{l}
w_{r}=U_{r}+\alpha_{1}\left(w_{A}-U_{r}\right) \\
w_{a}=U_{a}+\alpha_{2}\left(\Delta-U_{a}\right)
\end{array}\right\} \text { with } 0.2<\alpha_{1} \leq 0.5 \text { and } 0.2<\alpha_{2} \leq 0.5 .
$$

Offers below the lower threshold will seldom be made and will frequently be rejected; offers larger than the upper threshold will seldom be made.

However, for the interdependent ultimatum game between $P$ and $A$, the revenue has to be divided between three parties in the temporary work agency relationship. Therefore, we expect the following effect.

\section{$\mathrm{H}_{2}$ (Adaptation of vertical fairness concerns to a higher number of responders):}

$A$ and $P$ react to the differing number of persons that share the pie by adapting the fairness standards known from two-player ultimatum games to the three-player ultimatum games: They divide the surplus production revenue not by half, but such that $P$ retains a share of about one-third for himself and $A$ receives approximately two-thirds to share with worker $r$. Therefore, each player earns roughly one-third of the surplus. As a consequence, the upper limit is two-thirds, i.e., the ratio that divides the surplus of the first ultimatum game by the relation of the number of the players participating in the subordinated ultimatum game and the number of the participating players in both games. For the lower limit, we expect - similarly to the two-person case - approximately 0.4 of the upper limit, yielding 0.266 . Therefore, we predict

$$
w_{A}=U_{A}+\beta\left(\Delta-U_{A}\right) \text { with } 0.266 \leq \beta \leq 0.66 .
$$

Smaller offers will seldom be made, and if made, they will frequently be rejected.

Hypotheses $\boldsymbol{H}_{\boldsymbol{1}}$ and $\boldsymbol{H}_{2}$ do not consider effects that are caused by horizontal fairness norms. At the other extreme, one could argue that vertical norms are dominated by horizontal fairness norms, i.e., equal payment for equal work. Equal payment for equal work could only be offered at the expense of the temporary work agency or at the expense of the regular employee. Thus, one could predict that vertical fairness norms will be neglected using the following hypothesis. 


\section{$\mathrm{H}_{3}$ (Dominance of horizontal fairness norms):}

The wage offers to employee $a$ and temporary worker $r$ do not differ since they do the same work. Consequently,

$$
\frac{w_{r}}{w_{a}}=1
$$

However, given the strong experimental results on the relevance of vertical fairness concerns, it seems less plausible to assume that players exclusively pay attention to horizontal fairness norms. Therefore, the main purpose of our study is to show to which extent horizontal fairness norms interfere with vertical fairness concerns. In the treatment "staff", the ultimatum game between employer $P$ and employee $a$ takes place before the ultimatum game between agency $A$ and temporary worker $r$. Thus, $a$ has to make his decision, while ignoring the direct horizontal wage comparisons between the two workers. In the treatment "temp", the information about agency $A$ 's offer to hire employee $r$ and $r$ 's acceptance decision is available to $a$. Thus, a comparison of the behaviour for $a$ between the two treatments reveals the additional effect of a social comparison between $a$ and $r$. For $r$, the same effect could be relevant: While he decides without any information about $P$ 's offer to $a$ and $a$ 's reaction in the treatment "temp", this information is added in the treatment "staff": specifically, there exists an additional possible focus for horizontal fairness concerns. Therefore, we predict

\section{$\mathrm{H}_{4}$ (Effects of adding horizontal wage information):}

Adding a reference point for the horizontal fairness concerns of workers changes acceptance rates - in comparison to the case in which there is no horizontal information - in two possible ways: On the one hand, due to a favourable horizontal comparison, e.g., $w_{\mathrm{r}} / w_{\mathrm{a}} \geq 1$ for $r$ in the "staff" treatment, one could argue that social comparison (or self-regarding horizontal fairness concerns) makes offers acceptable that would have been below the acceptance threshold were no information available. Similarly, due to an inauspicious horizontal comparison, e.g., $w_{\mathrm{a}} / w_{\mathrm{r}}$ $<1$ for $a$ in the "temp" treatment, offers are not acceptable that would have been above the acceptance threshold were no information available. On the other hand, one could argue that players may care about a decent ratio on offers that do not discriminate against either of the two players. We refer to this idea as the other-regarding needs. Hence, a ratio $w_{\mathrm{r}} / w_{\mathrm{a}}\left(w_{\mathrm{a}} / w_{\mathrm{r}}\right.$, respectively) which differs substantially from one leads to rejections, although the underlying offer would be acceptable if observed without consideration of the social comparison. 
Finally, in their social-comparison, three-person ultimatum game, Knez and Camerer (1995) observe high rejection rates under multiple fairness foci and interpret this as a result of egocentric selection processes. While proposers select fairness standards which lead to relatively low offers, responders focus on reference points which lead to high offers, and therefore reject the lower offers more frequently than in the simple ultimatum game. We have to stress that in this experiment offers were made simultaneously. In contrast, we argue that $P$ and $A$ players in our setting consider the influence of the horizontal fairness concerns of players $a$ and $r$ since offers are made sequentially.

\section{$\mathrm{H}_{5}$ (Anticipation of fairness foci):}

$P$ and $A$ players in the experiment anticipate the effects of the social comparisons of employees in the "temp" treatment and of temporary employees in the "staff" treatment. Players $r$, who decide about the wage in the "staff" treatment, receive a premium in addition to their wages, while player $a$ suffers a wage reduction in the "temp" treatment.

\section{Results}

We first look at the average offers for both treatments, which are shown in Table 1. Obviously, offers do not follow the game-theoretic prediction. Additionally, average offers to $a$ are larger than wage offers to $r$. We find that both accepted and overall offers $w_{\mathrm{A}}, w_{\mathrm{a}}$ and $w_{\mathrm{r}}$ are significantly higher in the "staff" treatment than in the "temp" treatment. ${ }^{10}$ Since $P$ earns the residuals of the ultimatum games, the average pay-off for $P$ is smaller in the "staff" treatment than in the "temp" treatment.

\begin{tabular}{|c|c|c|}
\hline Averages & staff & temporary \\
\hline$(\mathrm{sd})$ & $(2.25)$ & (3.16) \\
\hline$w_{\mathrm{A}} \mid \delta_{\mathrm{A}}=1 \quad(\mathrm{sd})$ & $(1.94)$ & $(2.74)$ \\
\hline$w_{\mathrm{a}} \quad(\mathrm{sd})$ & $\begin{array}{ll}8.94 & (2.70)\end{array}$ & $(2.84)$ \\
\hline$w_{\mathrm{a}} \mid \delta_{\mathrm{a}}=1 \quad(\mathrm{sd})$ & $(2.59)$ & $(2.91)$ \\
\hline$w_{\mathrm{r}}$ & $(1.94)$ & $(2.01)$ \\
\hline$w_{\mathrm{r}} \mid \delta_{\mathrm{r}}=1 \quad(\mathrm{sd})$ & (1.84) & $(2.03)$ \\
\hline
\end{tabular}

Table 1: Average and average accepted offers

The analysis for $\boldsymbol{H}_{\boldsymbol{I}}$ tries to find the relation between our experimental observation and the standard results of ultimatum games. Hereby, we focus on vertical fairness aspects. For this purpose, we have to determine the number of observations that fall within the parameters 
of the acceptance threshold $\alpha$. Indeed, for employees, we find approximately 86 percent in the "staff" treatment and 83 percent in the "temp" treatment, respectively, of all $w_{\mathrm{a}}$ that fall only within this interval. Moreover, considering the rejection rates for offers, as shown in Figure 1(a), we have to confirm $\boldsymbol{H}_{1}$ for employees in the "staff" treatment since we find a dramatic increase in the frequency of rejection for $\alpha<0.2$. Thus, for the "staff" treatment, it seems that there is an acceptance threshold of approximately $\alpha=0.2$, which corresponds to offers of 7 . However, the rejection rate in the "temp" treatment looks rather different. Here, even for offers smaller than 7 , there is no dramatic increase in the frequency of rejection.

For temporary employees, we have to differentiate between the cases in which agencies reject the offer of $\mathrm{P}$ and the cases in which agencies accept their offers. ${ }^{11}$ Again, we find the majority of stated offers are within the limits suggested if agencies reject (94 percent for the "staff" and 91 percent for the "temp" cases). When the agencies accept $w_{\mathrm{A}}$, however, in the "staff" treatment (the "temp" treatment), they choose $w_{\mathrm{r}}$ in 73 percent (70 percent) of the cases from the interval defined in equation (8).
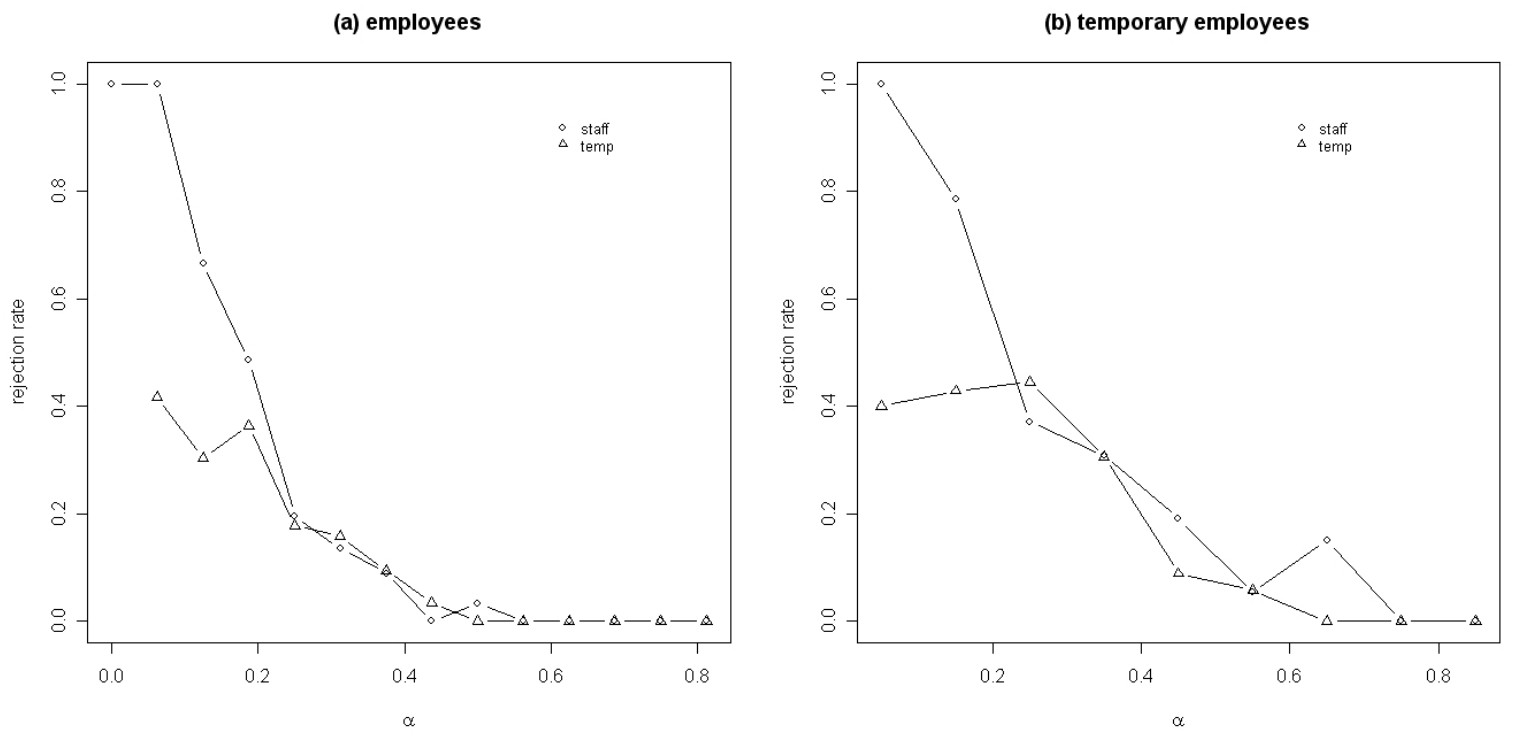

Figure 1: Rejection rates of (a) employees and (b) temporary employees

As shown in Figure 1(b), the rejection rates again suggest a rejection threshold of approximately $\alpha=0.2,{ }^{12}$ although the structure is not as clear as for employees. Quite surprisingly, in the "temp" treatment, the rejection by temporary workers follows the same

\footnotetext{
${ }^{10}$ For all differences, we find $p<0.01$, using two-sided Wilcoxon signed rank test for offers and using two-sided Mann-Whitney test for accepted offers.

${ }^{11}$ In the former case, the limits are $6>w_{\mathrm{r}}>3$, while in the latter case, we have $0.5+0.5 w_{\mathrm{A}}>w_{\mathrm{r}}>0.8+0.2 w_{\mathrm{A}}$.

${ }^{12}$ Here, the data of cases that agencies reject and that agencies accept is pooled.
} 
unusual structure as for employees. Our interpretation is that the more complicated ultimatum game between agencies and temporary employees makes it more difficult to see a clear structure regarding what is considered to be acceptable and what is not. ${ }^{13}$ Then social comparison transfers this ambiguity to employees. The opposite effect applies for the "staff" treatment. Here, the clear-cut structure of rejection thresholds for employees is transferred over to temporary employees. Overall, the data do not reject $\boldsymbol{H}_{\boldsymbol{I}}$ for employees and temporary employees in the "staff" treatment. Yet, rejection behaviour in the "temp" treatment differs substantially.

With respect to $\boldsymbol{H}_{2}$, we find a different pattern. Only 57 percent of all observations for $w_{\mathrm{A}}$ in the "staff" treatment, and even less, only 29 percent in the "temp" treatment, are within the predicted range. This result may indicate that behaviour in the independent ultimatum game does differ quite substantially from observed behaviour in standard ultimatum games. Note that the median $\beta$ for the "temp" treatment is 0.222 , while it is 0.333 for the "staff" treatment. Therefore, offers are much lower than observed in standard games. With respect to the rejection rate of agencies for $w_{\mathrm{A}}$ as shown in Figure 2, we do not observe a clear-cut acceptance threshold. There is no threshold to be observed since there is no step-wise increase in the rejection rate as offers decrease. There is little difference between rejections in the "staff" treatment and rejections in the "temp" treatment. Thus, there is no difference for agencies across the two treatments. In general, we find little experimental evidence supporting $\boldsymbol{H}_{2}$, i.e., that offers in the ultimatum game between $P$ and $A$ are only adapted to the higher number of responders. Behaviour differs quite substantially from what could be predicted on the basis of standard ultimatum games.

\footnotetext{
${ }^{13}$ When agencies accept their offers, one may argue that temporary employees reject offers since they consider the fraction that agencies earn from the entire production, i.e., $\left(w_{\mathrm{A}}-w_{\mathrm{r}}\right) / 19$, as being unfair. However, since the correlation between the acceptance on the part of temporary employees and this ratio for the cases in which agencies accept their offers does not differ significantly from zero for both treatments (-0.17 for the "staff" treatment, and -0.12 for the "temp" treatment; two-sided Pearson correlation tests cannot reject the hypothesis that correlations equal zero on an $\alpha=0.05$ level), we will not focus on this issue in the following analysis.
} 


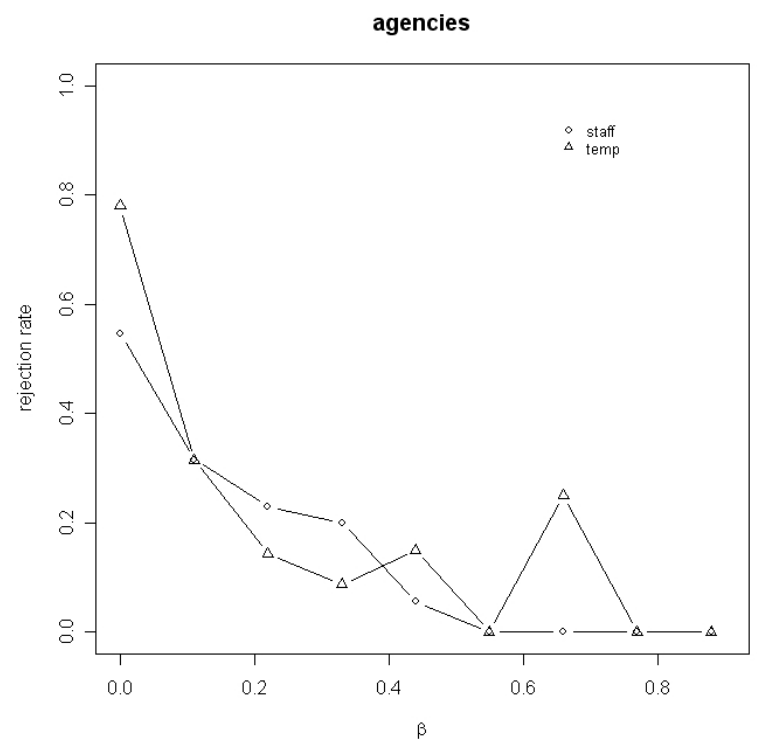

Figure 2: Rejection rates of agencies

For the analysis of $\boldsymbol{H}_{3}$, we have to consider the effects of horizontal fairness concerns. One theoretical possibility is that horizontal fairness norms between workers could completely offset vertical fairness issues. As mentioned earlier, we do not expect to find this dominance. The average development of $w_{\mathrm{r}} / w_{\mathrm{a}}$ throughout the entire experiment is shown in Figure 3.

(a) all offers

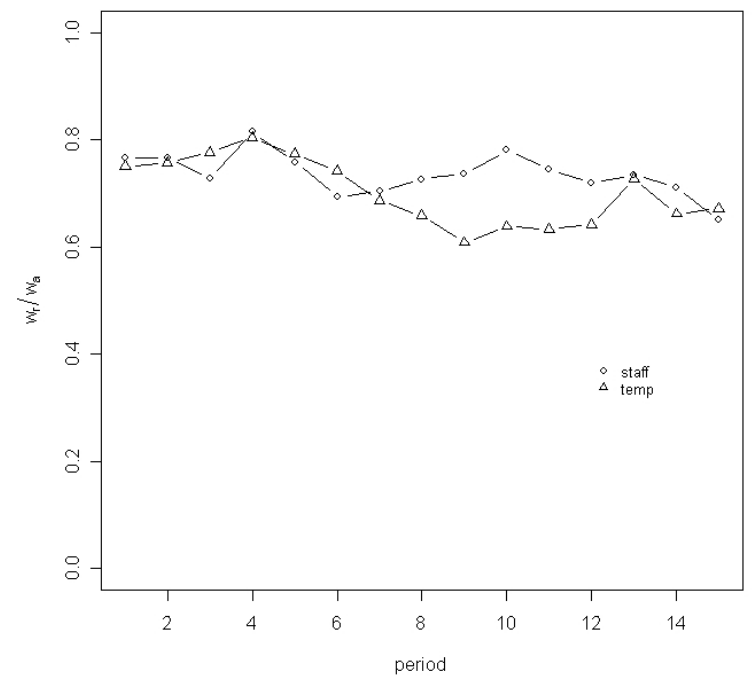

(b) only accepted offers

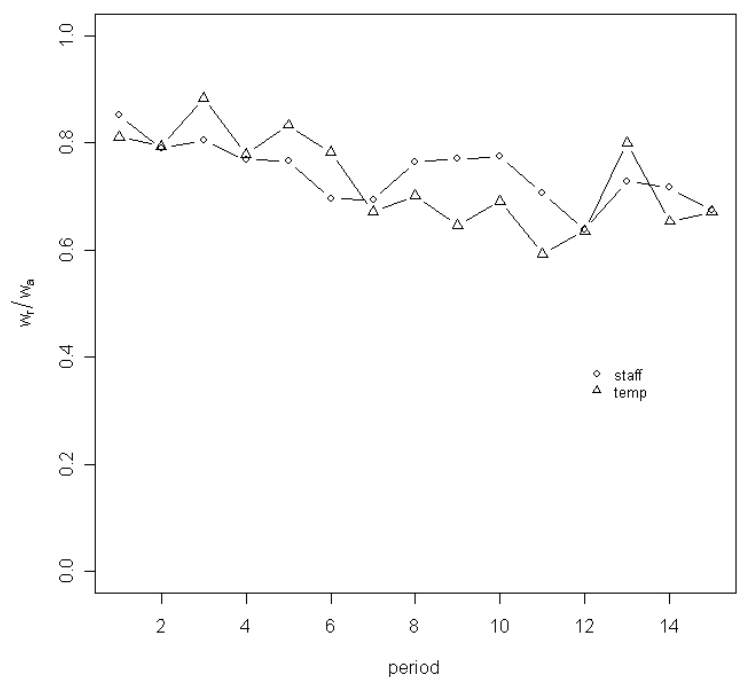

Figure 3: The average relation $w_{\mathrm{r}} / w_{\mathrm{a}}$ across periods (a) of all offers and (b) of offers that were accepted by a and ronly.

Neither the ratio based on all offers (shown in Figure 3(a)) nor the ratio based on accepted offers only (shown in Figure 3(b)) supports $\boldsymbol{H}_{3}$. However, we find a stable ratio $w_{\mathrm{r}} / w_{\mathrm{a}}$ in both treatments. Even if we only consider offers that were accepted by employee $a$ 
and temporary worker $r$, there is no significant difference between the ratios in the "staff" treatment and in the "temp" treatment. ${ }^{14}$ Of course, in general, $w_{\mathrm{r}}$ will be smaller than $w_{\mathrm{a}}$, as the surplus that can be divided between agency $A$ and worker $r$ is much smaller than the surplus that can be divided between employer $P$ and employee $a$. Thus, the ratio does not support the claim of equal payment for equal work; but we find that - considering the results for accepted offers only - a wage ratio between 0.7 and 0.8 is acceptable.

So far, we have seen that there is a quite stable ratio between wage offers for $a$ and $r$. Therefore, it seems important to clarify the extent to which horizontal fairness concerns can "substitute" for vertical fairness concerns. $\boldsymbol{H}_{4}$ aims at this question and states that adding a reference point for horizontal fairness concerns results in wage offers that are acceptable (inacceptable) in the no-horizontal-information treatment, but inacceptable (acceptable) in the information treatment. In order to test the experimental data for this question, we run a series of logit estimations for the rejection decisions $\delta_{\mathrm{a}}$ and $\delta_{\mathrm{r}}$. Of course, we have to consider that there are important interpersonal differences. Therefore, we estimate two individual fixed effects models with dependent variables $\delta_{\mathrm{a}}$, and $\delta_{\mathrm{r}}$, respectively. Let us define the dummy variable as $\sigma=0$ if observations are from the "staff" treatment and as $\sigma=1$ if observations are from the "temp" treatment. As independent variables indicating vertical fairness concerns, we use the ratio $\alpha_{\mathrm{i}}$ for $\mathrm{i}=1,2$, as defined in equation (8). We can predict a positive coefficient for $\alpha_{\mathrm{i}}$ in both models, i.e., the positive influence of $\alpha_{\mathrm{i}}$ on both variables $\delta_{\mathrm{a}}$, and $\delta_{\mathrm{r}}$. However, we expect vertical fairness considerations to have less influence on $\delta_{\mathrm{a}}$ in the "temp" treatment than in the "staff" treatment, i.e., $\alpha_{\mathrm{i}}$ to have a lower influence on $\delta_{\mathrm{a}}$ if $\sigma=1$, whereas the influence of vertical fairness considerations on $\delta_{\mathrm{r}}$ in the "temp" treatment is stronger than in the "staff" treatment, i.e., $\alpha_{\mathrm{i}}$ to have a higher influence on $\delta_{\mathrm{r}}$ if $\sigma=1$. Results for this estimation are reported as models $v$ in Table 2 . Additionally, we test the ratio $w_{\mathrm{r}} / w_{\mathrm{a}}$, indicating horizontal fairness concerns in the information treatments, i.e., in "staff" for variable $\delta_{\mathrm{r}}$ and in "temp" for variable $\delta_{\mathrm{a}}{ }^{15}$ Yet, the direction of influence of horizontal fairness concerns differs considerably across the values of $w_{\mathrm{r}} / w_{\mathrm{a}}$ and players. One may think of two different lines of argumentation. We call one line social comparison needs. Here, horizontal fairness concerns improve the acceptability of offers if the ratio favours one's own payoffs. For this line we can

\footnotetext{
${ }^{14}$ On an $\alpha=0.05$ level, a two-sided Wilcoxon signed rank test cannot reject the hypothesis that ratios for all offers of both treatments are the same; on an $\alpha=0.05$ level, a two-sided Mann-Whitney test cannot reject the hypothesis that ratios for the accepted offers of both treatments are the same.
} 
predict that the more the ratio favours temporary employees, the larger the positive influence of $w_{\mathrm{r}} / w_{\mathrm{a}}$ on $\delta_{\mathrm{r}}$. Thus, we can predict a positive coefficient for $w_{\mathrm{r}} / w_{\mathrm{a}}$ if $\sigma=0$. Likewise, we can argue that the more the inverse ratio $w_{\mathrm{a}} / w_{\mathrm{r}}$ favours employees, the larger the influence of $w_{\mathrm{a}} / w_{\mathrm{r}}$ on $\delta_{\mathrm{a}}$. Thus, we expect a positive coefficient for $w_{\mathrm{a}} / w_{\mathrm{r}}$ if $\sigma=1$. The estimation results for social comparison needs are reported as models $h_{\mathrm{soc}}$ in Table 2. Yet, the other line of argumentation suggests that players care about a decent ratio of offers, which does not discriminate against either of the two players. We call this line the other-regarding needs. Thus, the more the ratio $w_{\mathrm{r}} / w_{\mathrm{a}}$ (the inverse ratio $w_{\mathrm{a}} / w_{\mathrm{r}}$, respectively) deviates from one, the less acceptable the offers are. Hence, we define a variable that measures the quadratic distance from equal offers, i.e., $\tau_{1}=\left(w_{\mathrm{r}} / w_{\mathrm{a}}-1\right)^{2}$ and $\tau_{2}=\left(w_{\mathrm{a}} / w_{\mathrm{r}}-1\right)^{2}$. This measure is expected to show a negative coefficient. Results of the estimations are summarized as models $h_{\text {or }}$ in Table $2 ;{ }^{16}$ goodness of fit is reported by the Akaike information criterion (AIC).

\begin{tabular}{|c|c|c|c|c|c|c|c|c|}
\hline & $\delta_{a} \mid \sigma=0$ & \multicolumn{3}{|c|}{$\delta_{a} \mid \sigma=1$} & $\delta_{r} \mid \sigma=1$ & \multicolumn{3}{|c|}{$\delta_{r} \mid \sigma=0$} \\
\hline Model & $v$ & $v$ & $h_{\mathrm{soc}}$ & $h_{\mathrm{or}}$ & $v$ & V & $h_{\mathrm{soc}}$ & $h_{\mathrm{or}}$ \\
\hline constant & $\begin{array}{l}-4.61 \\
(2.831)\end{array}$ & $\begin{array}{l}-2.03^{* *} \\
(0.816)\end{array}$ & $\begin{array}{c}-2.45 * * * \\
(0.777)\end{array}$ & $\begin{array}{c}-2.02 * * \\
(0.79)\end{array}$ & $\begin{array}{c}-2.28 * * * \\
(0.691)\end{array}$ & $\begin{array}{c}-2.03 * * * \\
(0.767)\end{array}$ & $\begin{array}{c}-2.53 * * * \\
(0.864)\end{array}$ & $\begin{array}{c}-2.37 * * \\
(1.01)\end{array}$ \\
\hline$\alpha_{\mathrm{i}}$ & $\begin{array}{c}22.88 * * * \\
(0.45)\end{array}$ & $\begin{array}{c}18.68^{* * * *} \\
(3.362)\end{array}$ & $\begin{array}{c}17.81 * * * \\
(3.333)\end{array}$ & $\begin{array}{l}18.3^{* * * *} \\
(3.355)\end{array}$ & $\begin{array}{c}10.77 * * * \\
(1.906)\end{array}$ & $\begin{array}{c}9.55^{* * * *} \\
(1.71)\end{array}$ & $\begin{array}{l}8.35^{* * * *} \\
(1.768)\end{array}$ & $\begin{array}{l}9.45^{* * * *} \\
(2.078)\end{array}$ \\
\hline $\begin{array}{l}w_{\mathrm{a}} / w_{\mathrm{r}} \\
w_{\mathrm{r}} / w_{\mathrm{a}}\end{array}$ & & & $\begin{array}{l}0.74 * * \\
(0.334)\end{array}$ & & & & $\begin{array}{l}1.38 * * * \\
(0.534)\end{array}$ & \\
\hline$\tau_{1}$ & & & & $\begin{array}{c}0.11 \\
(0.168)\end{array}$ & & & & $\begin{array}{c}-0.06 \\
(1.396)\end{array}$ \\
\hline$A I C$ & 173 & 191 & 188 & 193 & 269 & 274 & 270 & 276 \\
\hline
\end{tabular}

Table 2: Logit regression results for coefficients

\footnotetext{
${ }^{15}$ We set the ratios equal to zero for all observations where responders who had to decide first rejected the offer, i.e., $\delta_{\mathrm{a}}=0$ in the "staff" treatment and $\delta_{\mathrm{r}}=0$ in the "temp" treatment.

${ }^{16}$ Standard errors in parenthesis; $* * *$ significant on $\alpha=0.01$ level, ** significant on $\alpha=0.05$ level, * significant on $\alpha=0.1$ level.
} 
As expected, contract acceptance by employee $a$ is strongly and significantly influenced in a positive way by vertical fairness concerns $\left(\alpha_{\mathrm{i}}\right)$ in both treatments. Confirming our predictions, vertical fairness concerns are higher when no information is available, i.e., $\sigma$ $=0$. On the other hand, horizontal fairness concerns in the sense of social comparison, i.e., $w_{\mathrm{a}}$ $/ w_{\mathrm{r}}$, show a significant positive influence on $a$ 's contract acceptance if player $r$ decides first. However, the insignificant variable $\tau_{1}$ indicate that horizontal fairness concerns follow the idea of social comparison rather than other-regarding needs. Hence, we find a substitution effect for some $w_{\mathrm{a}}$ offers. For an offer $w_{\mathrm{a}}$, which is acceptable if no horizontal information is provided, the probability that $a$ will accept decreases in the information treatment as the ratio $w_{\mathrm{a}} / w_{\mathrm{r}}$ decreases. For the offer acceptance by temporary employee $r$, vertical fairness concerns strongly and significantly influence the probability that a temporary employee will accept a contract. The higher $\alpha_{\mathrm{i}}$ is, the higher the probability of acceptance. Again, this effect is less pronounced in the information treatment, i.e., $\sigma=0$. Here, horizontal fairness concerns matter quite a lot. The higher the ratio $w_{\mathrm{r}} / w_{\mathrm{a}}$, the higher the probability that $r$ will accept the offer. For an offer $w_{\mathrm{r}}$ which is inacceptable if no horizontal information is provided, the probability that $r$ will accept increases in the information treatment as the ratio $w_{\mathrm{r}} / w_{\mathrm{a}}$ increases. Again, social comparison matters, but we do not find other regarding needs to have a significant effect. Summarising the results of the estimation models, we can support $\boldsymbol{H}_{4}$, i.e., that vertical and horizontal fairness considerations are substituted for one another. This effect refers to some social comparison; that is, an offer is acceptable due to a favourable comparison to another player's offer, although the offer may not be acceptable if no comparative information is available.

With respect to $\boldsymbol{H}_{5}$, we claim that rejection rates do not increase under multiple fairness foci because proposers adapt their offers, anticipating the horizontal fairness concerns of responders. Therefore, we consider the development of efficiency and payoffs across experimental periods. Please note that the efficiency provides a mirror image of rejections. Whenever offers are rejected, efficiency is decreased. Figure 4(a) shows average overall efficiency, while we normalized efficiency such that 0 efficiency characterizes the case in which player $a$ and player $r$ reject their offers. Figure 4(b) reports the development of efficiency within the ultimatum game between $P$ and $a$. Finally, Figure 4(c) shows the development of efficiency within the ultimatum game between $A$ and $r$. As one can see, there is no difference between the treatments for efficiency in general and for the separate 
ultimatum games. A non-parametric test supports this hypothesis. ${ }^{17}$ Moreover, we do not observe a clear time effect. Efficiency remains at approximately 80 percent throughout the entire experiment.

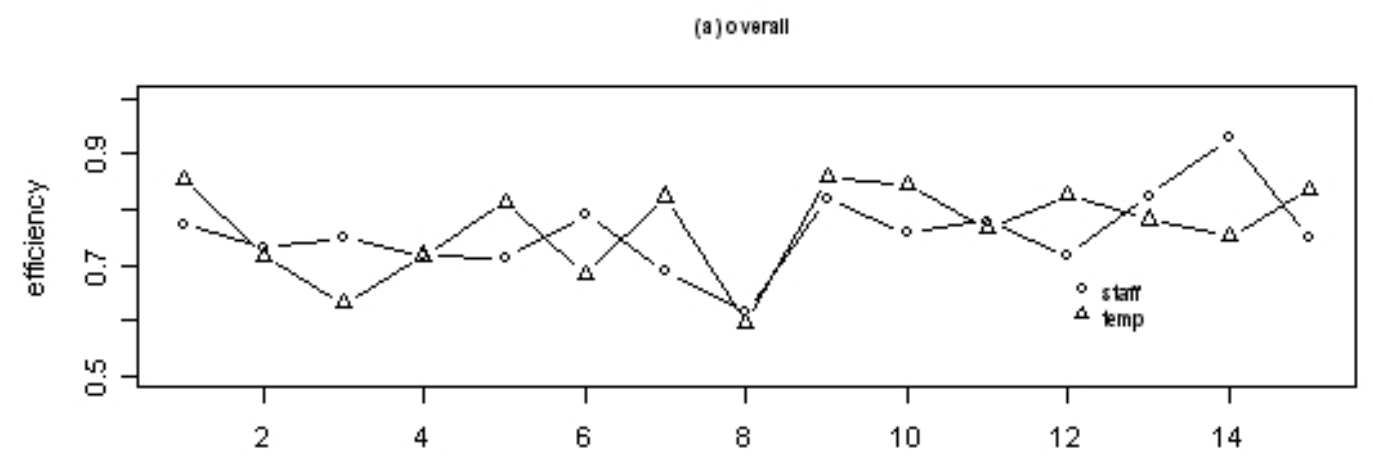

(b) $P$ and a

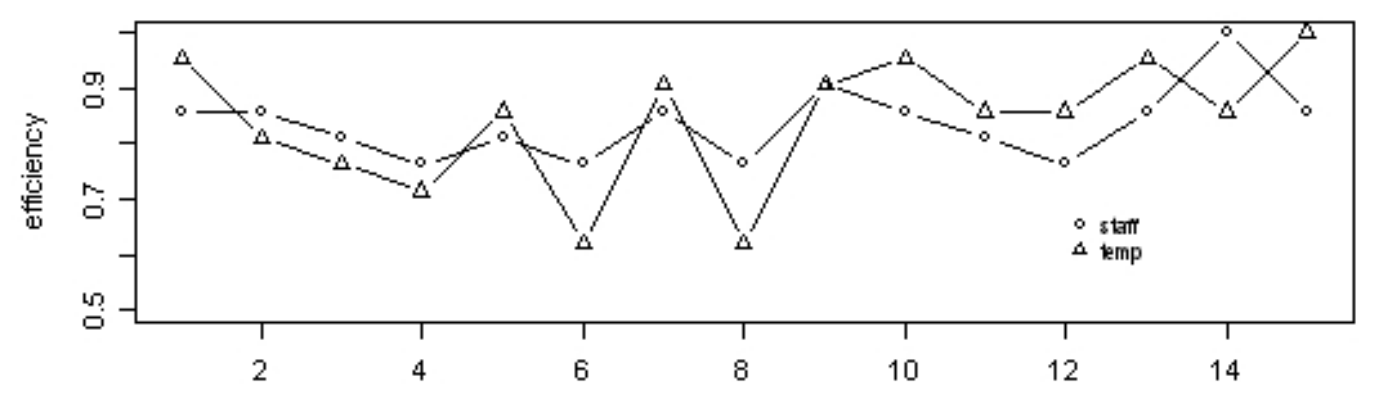

(c) $A$ and $r$

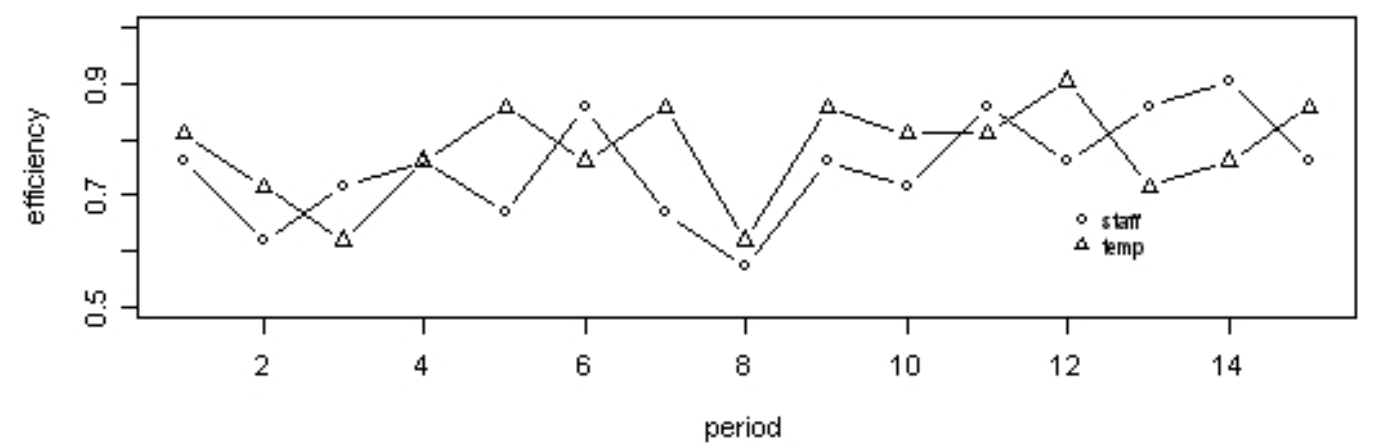

Figure 4: Average efficiency per period (a) overall, (b) within ultimatum game between $P$ and $a$, and (c) within the ultimatum game between $A$ and $r$ throughout the experiment

However, we find a treatment effect with respect to the distribution of earnings. Figure 5(a) compares the earnings of player $P$ and player $A$ across treatments and periods. As one can

\footnotetext{
${ }^{17}$ Two-sided Wilcoxon signed rank tests cannot reject the hypothesis of equal efficiency on an $\alpha=0.05$ level.
} 
see, on average player $P$ receives lower earnings in the "staff" treatment than in the "temp" treatment. Indeed, a non-parametric test confirms this result. ${ }^{18}$ Although we found earlier that the average offer $w_{\mathrm{A}}$ is significantly higher in the "staff" treatment than in the "temp" treatment, Figure 5(a) illustrates that player $A$ does not earn more in the "staff" treatment than in the "temp" condition. ${ }^{19}$ Thus, the premium is transferred to player $r$. In particular, as one can see in Figure 5(b), the earnings for both player $a$ and player $r$ are higher in the "staff" treatment. Again, a non-parametric test confirms this result. ${ }^{20}$ Thus, one could say that temporary employees receive a premium payment in the "staff" treatment in order to satisfy their horizontal fairness concerns. To the contrary, employees suffer a significantly lower income in the "temp" treatment than in the "staff" treatment. ${ }^{21}$ Average earnings are significantly lower if temporary agents decide first about their wage offer; they are higher if the decision of the employees comes first.
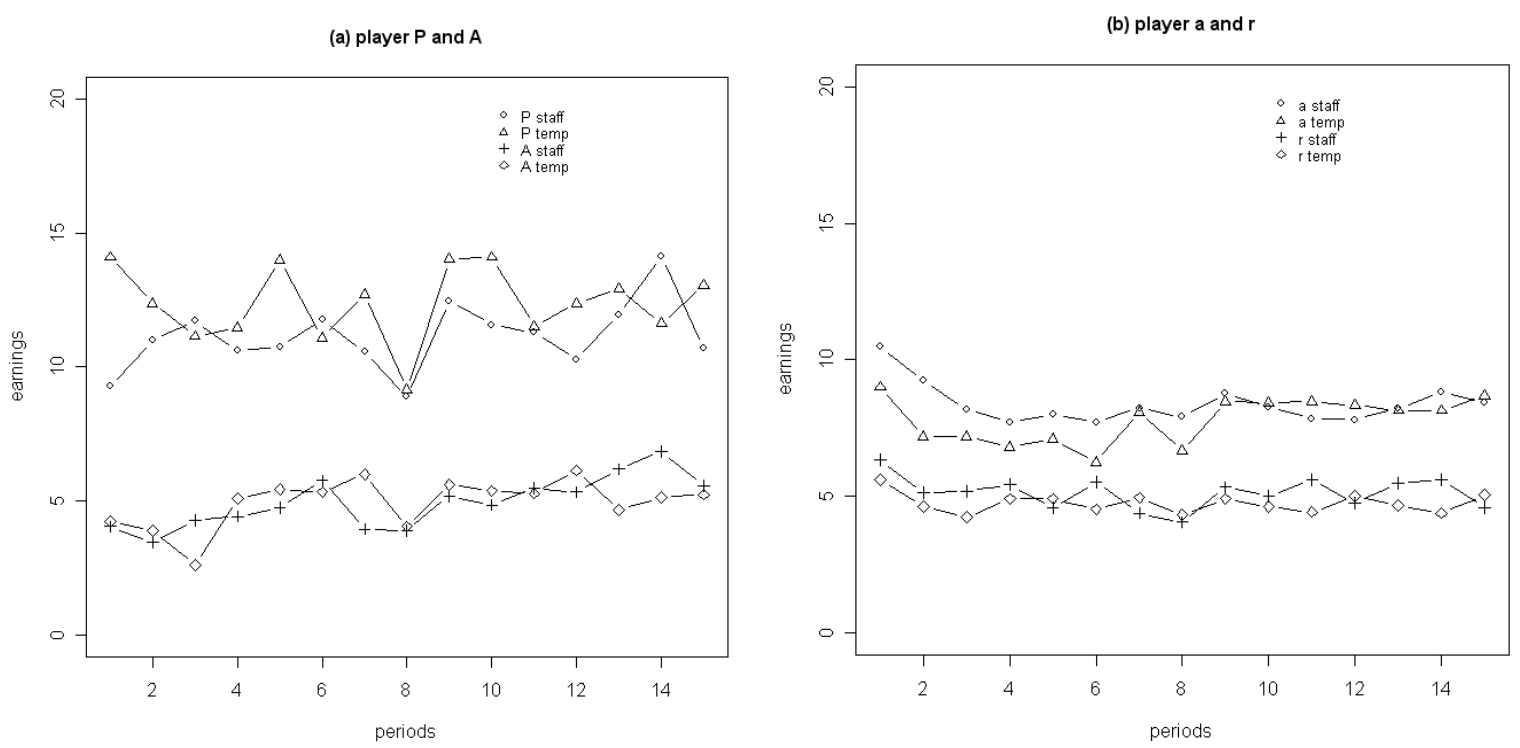

Figure 5: Average earnings of (a) of players $P$ and $A$ and $(b)$ of players $a$ and $r$ per period throughout the experiment

Evidently, these results confirm $\boldsymbol{H}_{5}$. Proposers adapt their offers to the different fairness foci. Moreover, one could indeed speak of some kind of first responder advantage due to horizontal fairness concerns, e.g., self-regarding social comparison needs. The data show that proposers try to maintain stable ratios between offers across treatments. Thus,

\footnotetext{
${ }^{18}$ A one-sided Wilcoxon signed rank test rejects the hypothesis of equal efficiency on an $\alpha=0.05$ level.

${ }^{19}$ A two-sided Wilcoxon signed rank test confirms this claim since it cannot reject the hypothesis of equal efficiency on an $\alpha=0.05$ level.

${ }^{20}$ A one-sided Wilcoxon signed rank test rejects the hypothesis of equal efficiency on an $\alpha=0.05$ level.

${ }^{21}$ As earlier, a one-sided Wilcoxon signed rank test rejects the hypothesis of equal efficiency on an $\alpha=0.05$ level.
} 
responders receive a premium if their focus is on the decisions of other responders with higher outside options. However, those responders who focus on decisions of other responders with lower outside options suffer a loss in their incomes since they accept lower wage offers due to their horizontal comparison.

\section{Conclusion}

Apparently, fairness concerns matter for economics. And they have indeed been studied extensively by economists over the last decades. However, the overwhelming majority of those studies have focussed exclusively on the issue of vertical fairness considerations. Yet, social comparison and the resulting horizontal fairness concerns are important in most areas of our lives. Our experimental results demonstrate the combined relevance of vertical and horizontal fairness foci in interrelated ultimatum games. However, the sequential order of decisions and bargaining steps, which determines the available information for horizontal comparison, is crucial for determining the relevance of horizontal fairness concerns. Therefore, there are effects that favour the payoffs of the second responder, but also effects that decrease the payoffs of second responders.

If the worker with lower outside options bargains on the smaller pie, i.e., if temporary employee $r$ and agency $A$ bargain, and workers with higher outside option observe the outcome of the bargaining, i.e., employee $a$, the effect of this sequential order is disadvantageous for both workers. Those players who have lower outside options accept offers due to vertical fairness concerns. Yet, players with higher outside options accept wages due to their horizontal comparison. By contrast, if workers with higher outside options choose first, the opposite occurs for both workers. Yet it harms proposers, i.e., player $P$. Here, responders with lower outside options ask for higher wage offers based on their horizontal fairness concerns.

As we could show in this experiment, behaviour is influenced in important ways by horizontal fairness norms. In particular, in our study we focussed on the interplay between vertical and horizontal fairness considerations related to wage decisions. The high relevance of combined vertical and horizontal fairness foci for labour economics is obvious. Since the topic of temporary agency work, and, therefore, commonly, heterogeneous versus homogenous payment for similar work, is at the centre of extensive political discussion in the 
European Union, the significance of effects of multiple fairness foci is increasing rather than disappearing. Yet, the co-employment of permanent and temporary workers is only one example from a wider class of situations. Firms and groups offer multiple sources for fairness foci.

\section{References}

Alewell, D., C. Friedrich \& S. Martin (2004), Gleichbehandlungsgrundsatz: Ende der Zeitarbeit? Ausgewählte betriebliche Wirkungen der Zeitarbeit aus ökonomischer Perspektive. In: Struck, O. \& C. Köhler (eds.), Beschäftigungsstabilität im Wandel; empirische und theoretische Befunde, München, Mering, p. 227246.

Babcock, L., X. Wang \& G. Loewenstein (1996), Choosing the wrong pond: Social comparisons in negotiations that reflect a self-serving bias, The Quarterly Journal of Economics, 111(1), 1-19.

Bagwell, K. (1995), Commitment and observability in games, Games and Economic Behavior 8, 271-280.

Bolton, G.E. \& A. Ockenfels (2000), ERC: A theory of equity, reciprocity, and competition, American Economic Review 90(1), 166-193.

Camerer, C.F.(2003), Behavioral game theory; Princeton: Princeton University Press.

Charness, G. \& P. Kuhn (2004), Do co-workers' wages matter? Theory and evidence on wage secrecy, wage compression and effort, IZA Discussion Paper 1417

Dickinson, D.L. \& J. Tiefenthaler (2002), What is fair? Experimental evidence, Southern Ecoomic Journal. 69(2), 414-428.

Fehr, E. \& K.M. Schmidt (1999), A theory of fairness, competition, and cooperation, The Quarterly Journal of Economics, 114(3), 817-868.

Fischbacher, U. (1999), z-Tree - Zurich toolbox for readymade economic experiments - Experimenter's manual, Working Paper 21, Institute for Empirical Research in Economics, University of Zurich.

Gächter, S. \& E. Fehr (2002), Fairness in the labour market: A survey of experimental results. In: Bolle, F. \& M. Lehmann-Waffenschmidt (eds.), Surveys in experimental economics: Bargaining, cooperation and election stock markets, Heidelberg: Springer, 95-132.

Greiner, B. (2004), An online recruitment system for economic experiments. In: Kremer, K. \& V. Macho (eds.), Forschung und wissenschaftliches Rechnen 2003, Bericht der Gesellschaft für wissenschaftlichen Datenverarbeitung Göttingen 63, 79-93.

Güth, W., S. Huck \& W. Müller (1998), The relevance of equal splits: On a behaivoral discontinuity in ultimatum games, Discussion Paper Sonderforschungsbereich 373, Humboldt- University Berlin.

Güth, W., R. Schmittberger \& B. Schwarze (1982), An experimental analysis of ultimatum bargaining, Journal of Economic Behavior and Organization 3, 367-388.

Güth, W. \& T. Tietz (1990), Ultimatum bargaining behavior: A survey and comparison of experimental results, Journal of Economic Psychology 11, 417-449.

Huck, S. \& W. Müller (2000), Perfect versus imperfect observability: An experimental test of Bagwell's result, Games and Economic Behavior 31, 174-190.

Kahnemann, D., J.L. Knetsch \& R. Thaler (1986), Fairness as a constraint on profit seeking: Entitlements in the market, American Economic Review 76(4), 728-741.

Knez, M.J. \& C.F. Camerer (1995), Outside options and social comparison in three-player ultimatum game experiments, Games and Economic Behavior 10, 65-94.

Konow, J. (1996), A positive theory of economic fairness, Journal of Economic Behaviour and Organization 31, 13-35.

Konow, J. (2000): Fair shares: Accountability and cognitive dissonance in allocation decisions, American Economic Review 90(4), 1072-1091. 
Konow, J. (2001), Fair and square: The four sides of distributive justice, Journal of Economic Behavior and Organization 46, 137-164.

Konow, J. (2003), Which is the fairest one of all? A positive analysis of justice theories, Journal of Economic Literature 41, 1188-1239.

Leventhal, G.S. (1980), What should be done with equity theory? New approaches to the study of fairness in social relationships. In: Gergen, G.S., M.S. Greenberg \& R.H. Willis (eds.), Social Exchange, Advances in Theory and Research, New York: Plenum Press, p. 27-55.

Rabin, M. (1993), Incorporationg fairness into game theory and economics, American Economic Review 83(5), 1281-1302.

Schelling, T. (1960), The strategy of conflict, Cambridge, M.A.: Harvard University Press.

Scott, P. (2003), Fairness as a source of hysteresis in employment and relative wages, Discussion Paper, University of Massachusttes. 


\section{Appendix A - Translation of the instructions for "temporary" treatment ${ }^{22}$}

Thank you very much for participating in this experiment. Please refrain from talking to or communicating with other participants in any way during the experiment. Please note that we have to exclude you from further participation if you break this rule. If you have any questions, please raise your hand. One of the experimentators will then privately answer your questions. Please read these instructions very carefully.

In this experiment, you will make decisions by which you can earn money. How much you will earn depends on your decisions and the decisions of other participants. During the experiment, you can earn points, which will be exchanged for Euros at the end of the experiment. The exchange rate is 24 points for 1 Euro. Additionally, each of you will receive 4 Euro independent of the number of points you earn in the experiment.

At the beginning of the experiment you will be assigned a role, e.g., a task, by chance. This role remains unchanged for the complete duration of the experiment. In total, you will interact with the other participants for 15 rounds. In each round, three other participants will be anonymously assigned to your group by chance.

The roles of the four different types of participants are labeled firm, agency, employee and temporary worker. The firm can produce products with her employee and/or with the temporary worker and gain profits. The agency can hire the temporary worker and hire him out to the firm or other firms. Specifically, each participant has the following tasks:

- The firm has to offer to the agency the fee $\mathrm{w}_{\mathrm{A}}$ to hire the temporary worker. Additionally, it has to make an offer $\mathrm{w}_{\mathrm{a}}$ to the employee.

- The agency has to accept or reject the firm's fee offer $\mathrm{w}_{\mathrm{A}}$. Additionally, it has to make an offer $\mathrm{w}_{\mathrm{r}}$ to the temporary worker. The agency can cancel temporary contracts with the firm if it has not succeeded in contracting with the temporary worker.

- The employee has to accept or reject the firm's offer $\mathrm{w}_{\mathrm{a}}$.

- The temporary worker has to accept or reject the agency's wage offer $\mathrm{w}_{\mathrm{r}}$.

The payoffs of the participants are calculated as follows:

- If the employee accepts wage offer $\mathrm{w}_{\mathrm{a}}$, he earns $\mathrm{w}_{\mathrm{a}}$ points; otherwise he earns 3 points from other sources.

\footnotetext{
${ }^{22}$ This is a translation of the original German instructions. Changes in the "staff" treatment are indicated by footnotes.
} 
- If both the agency and the temporary worker accept their offers $\mathrm{w}_{\mathrm{A}}$ and $\mathrm{w}_{\mathrm{r}}$, the agency earns $\mathrm{w}_{\mathrm{A}}-\mathrm{w}_{\mathrm{r}}$ points. If the temporary worker accepts his offer $\mathrm{w}_{\mathrm{r}}$, but the agency rejects the firm's offer $\mathrm{w}_{\mathrm{A}}$, the agency places the temporary worker with some other project and gets 10 points as a fee. The agency then receives a payoff of $10-\mathrm{w}_{\mathrm{r}}$ points. If the temporary worker rejects the agency's wage offer $\mathrm{w}_{\mathrm{r}}$, the agency earns nothing.

- If the temporary worker accepts the agency's wage offer $\mathrm{w}_{\mathrm{r}}$, he earns $\mathrm{w}_{\mathrm{r}}$ points (regardless of whether the agency accepts the firm's offer $\mathrm{w}_{\mathrm{A}}$ or not). If the temporary worker rejects the agency's wage offer $\mathrm{w}_{\mathrm{r}}$, he receives 1 point from other sources.

- If the agency, the temporary worker and the employee accept their offers $\mathrm{w}_{\mathrm{A}}, \mathrm{w}_{\mathrm{r}}$ and $\mathrm{w}_{\mathrm{a}}$, the firm can produce two units of products, and it thereby earns a revenue of 38 points. Its payoff is then $38-\mathrm{w}_{\mathrm{A}}-\mathrm{w}_{\mathrm{a}}$. If the employee rejects the firm's offer, but the temporary worker and the agency accept their respective offers, the firm can produce one product unit, and it thereby earns revenues of 19 points. Its payoff is then $19-\mathrm{w}_{\mathrm{A}}$. If the agency or the temporary worker or both reject their respective offers, but the employee accepts the firm's offer, the firm produces one product unit and earns revenues of 19 points. Its payoff is then $19-\mathrm{w}_{\mathrm{a}}$ points. If the employee and the agency or the temporary worker, or both, reject their offers, the firm cannot produce any product units, and it earns no revenue. Its payoff is then 0 points.

All offers have to be made in whole numbers. At the beginning of each period, the firm has to decide about its offers, $\mathrm{w}_{\mathrm{A}}$ and $\mathrm{w}_{\mathrm{a}}$, to the agency and to the employee, respectively. Then the agency is informed about these offers; it has to accept or reject $\mathrm{w}_{\mathrm{A}}$ and decide about its wage offer $\mathrm{w}_{\mathrm{r}}$. In the next step, we inform the temporary worker about the agency's offer $\mathrm{w}_{\mathrm{r}}$, the firm's offer $\mathrm{w}_{\mathrm{A}}$ to the agency and the agency's decision about $\mathrm{w}_{\mathrm{A}}$. The temporary worker then has to accept or reject the offer $\mathrm{w}_{\mathrm{r}}$. Then, the employee is informed about the firm's wage offer $\mathrm{w}_{\mathrm{a}}$ and about the offers and decisions of the agency and the temporary worker. On this basis, he has to accept or reject the offer $\mathrm{w}_{\mathrm{a}} \cdot{ }^{23}$ Finally, the firm and the agency receive the information on whether their offers have been accepted or not.

Please note that players may realise losses if they place disadvantageous offers. This could, for example, occur if the sum of the firm's offers to the agency and the employee exceeds the

\footnotetext{
${ }^{23}$ The last four sentences are changed in the "staff" treatment as follows:

"In the next step, we inform the employee about the firm's wage offer $\mathrm{w}_{\mathrm{a}}$, and the employee then has to accept or reject the offer $\mathrm{w}_{\mathrm{a}}$. Then the temporary worker is informed about $\mathrm{w}_{\mathrm{r}}$ and the firm's offer $\mathrm{w}_{\mathrm{A}}$ to the agency and the agency's decision about $\mathrm{w}_{\mathrm{A}}$. On this basis, he has to accept or reject the offer $\mathrm{w}_{\mathrm{r}}$."
} 
revenue from production of 38 points. Such losses in single periods will be balanced by profits in other periods. However, if you accumulate a negative pay-off after 15 rounds, we will ask you to pay your debts by working as a research assistant at our institute (96 points $=$ 1 working hour). If you do not agree to this condition, please leave the experiment now.

Before starting the experiment, we would like you to answer a short questionnaire privately. After 10 minutes, we will publicly present the correct solutions to all participants. 


\section{Appendix B - Translation of the questionnaire}

(1) Let us assume the following offers are made and accepted by the respective participants:

Hiring offer to the agency $=18$

Offer to the employee $=12$

Offer to the temporary worker $=15$.

How many points does the firm earn?
( ) 38
( ) $38-18-12-15$
( ) $38-18-12$
( ) $38-12-15$

How many points does the agency earn?
( ) 36
( ) 18
( ) $36-15$
( ) $18-15$

How many points does the employee earn?
( ) 12
( ) 15
( ) $38-12$
( ) $15-12$

How many points does the temporary worker earn?
( ) 12
( ) 15
( ) $38-12$
( ) $15-12$

(2) Let us assume in the situation described in question (1) that the agency rejects the fee offer of 18 , but the temporary worker accepts the offer 15 .

How many points does the firm earn?
( ) $19-15$
( ) $38-10-12-15$
( ) $19-12$
( ) 0

How many points does the agency earn?
( ) 18
( ) $18-15$
( ) 10-15 (the agency incurs a loss) ( ) 0

How many points does the temporary worker earn?
( ) 15
( ) 10-15 (the temporary worker incurs a loss)
( ) $19-15$
( ) 10

(3) Let us assume in the situation described in question (1) that the agency accepts the fee offer of 18, but the temporary worker rejects the offer of 15 .

How many points does the firm earn?
( ) 38-10-12 ( ) 19-12
( ) $38-12-15$
( ) 0

How many points does the agency earn?
( ) 18
( ) $18-15$
( ) 10-15 (the agency incurs a loss) ( ) 0

How many points does the temporary worker earn?
( ) 15
( ) 1
( ) 10-15 (the temporary worker incurs a loss)
( ) 0 